\title{
Improving E-Commerce Effectiveness Using Augmented Reality
}

\author{
Melati Rosanensi \\ Information Systems, Universitas Bumigora \\ E-Mail:Melati.rn@universitasbumigora.ac.id
}

\begin{abstract}
The research aims to increase the effectiveness of e-commerce using augmented reality so that it can be used for online sellers as an option for existing sales media. The target of the application of augmented reality kitchen tools such as plates, cups, bowls, and teapots which are small equipment are social media users (Instagram) such as housewives or career women who usually use smartphones. The approach taken to determine the e-commerce sales model by applying augmented reality technology is to refer to the results of the system tests conducted previously. The conversion process is carried out in the implementation of augmented reality-based e-commerce sales media by using the parallel conversion method, namely by implementing a new system alongside the old system. In this study using the reliability test method, normality test, and Wilcoxon different test paired samples. From the test results show that the data are in the area of rejection of Ho then accept $H_{1}$ which means that changes occur before and after using augmented reality, with the conclusion that an increase in the effectiveness of e-commerce using augmented reality, for this augmented reality application can be used on e-sales media commerce instagram to enhance technological progress.
\end{abstract}

Keywords: e-commerce, augmented reality, sales, increase, effectiveness.

Author Korespondensi (Melati Rosanensi)

Email:Melati.rn@universitasbumigora.ac.id

\section{INTRODUCTION}

Conventional trade in goods and services at this time has been largely abandoned by some people because it is considered ineffective and less efficient, people prefer something that is instant like when there is no time to go to the market because there is work so some people will choose to have online shop especially for career women, online shopping is now more popular by some people because it is considered efficient in cost and time [1]. Conventional trading has not been completely abandoned, especially for people in rural areas because access to the internet and transportation is still minimal, but it is different from urban communities that are caught by jam on the streets and require sufficient time to just go to the market to buy equipment or certain needs. Then, online shopping is one alternative that is much in demand. While conventional trade has slowly begun to be abandoned by some people, especially in urban areas, at the same time when people's needs for technological development are increasing that's when the internet is growing rapidly, even now the internet is widely used for everything in this world one of them in terms of trade in goods / services, with the internet many developers create various features and applications that are practical to use when buying and selling, buying and selling transactions automatically. Online shop is more commonly known as e-commerce [1]. ecommerce is an activity related to trade between goods, services and other business activities that are sustainable, through an electronic or technological media [2]. e-commerce is also often called an extension of commerce by exploiting an electronic media, although in general the use of electronic media is not yet widely understood, but business competition and pressure cause business people will inevitably have to follow and use this electronic media [2] e-commerce in general means that is all forms of trade / trade transactions between goods or services (trade of goods and services) using an electronic media that can be interpreted as a dynamic set of application technology and a business process as connecting between companies, consumers and certain communities through an electronic transaction and trade in 
goods, services and information that can be done electronically [3]. The use of E-commerce systems [2] can benefit many business people, both consumers, and producers and sellers (retailers), for many consumers when using Ecommerce consumers can make shopping time shorter, which is usually if conventional shopping must be urged- insistence when shopping, spending gasoline, and spending time on the road, since utilizing E-commerce no more spending long hours on the way to the store, no more spending on gasoline, no more wandering around the many shopping centers to find the desired items In addition, usually the prices of goods traded through E-commerce are cheaper than the prices of goods in conventional stores, because the path for distribution from the producer of goods to the seller of goods is shorter in time and cost compared to conventional stores.

e-commerce provides many conveniences and advantages to buyers when compared to conventional shopping. One of the advantages is that it can be faster and shorter in terms of time, online shopping has a lot of available types of goods that are usually sold in full, so that even though we will not buy goods online, but we can get a lot of important information very necessary to choose a product that you want to buy [4]. As in this study, researchers chose kitchen tools as the object of research because the target researchers were housewives and career women who did not have much time or did not have time to shop at conventional stores or malls, and housewives or women who preferred to online shop. But online shopping still rarely uses augmented reality, even though this AR technology can convey additional information through the internet and display it more real with the help of equipment such as webcams, computers, Android phones, and special glasses. Users in the real world cannot see virtual objects with the naked eye, to identify objects needed by intermediaries in the form of computers and cameras that will later insert virtual objects into the real world [5]. According to explanation [6] the augmented reality system must meet the following three characteristics: combining real and virtual content, the system is interactive and acts in real time; virtual content is registered with the real world. Based on the description above, the researchers hope to contribute in the form of satisfaction, understanding, and the level of interest in e-commerce users by applying augmented reality technology.

\section{METHODOLOGY}

\subsection{Data Analysis Method}

Data analysis method in this study is to compare the results of e-commerce development from before and after using augmented reality in the form of graphs or tables. On the graph or table you will see a decrease or increase in effectiveness, a decrease and increase in effectiveness will be seen from the results of the questionnaire distributed to followers of Instagram account kitchenzone through the reliability test, normality test and Wilcoxon different paired sample test.

\subsection{The types, characteristics and research approaches are as follows:}

a. Research development

This research is a development research that is: conducting a research in order to develop a product so that the product becomes better by providing additional augmented reality on e-commerce online kitchen appliance sales.

b. The nature of comparative causal research The purpose of this study are: comparing the effectiveness of e-commerce from before using augmented reality and after using augmented reality, the steps will be making 3D Modeling kitchen tools first then made augmented reality, then compare e-commerce before and after using augmented reality from the results of the questionnaire distributed to users. Will there be an increase in effectiveness from before using augmented reality and after using augmented reality.

c. Quantitative Approach

This study using a quantitative approach which later results from this research are information in the form of numbers (such as the results of the kitchenzone account followers questionnaire) from the results of the development that has been done. The data collection process that is carried out is the result of the development then the data is compared and analyzed, such as making 
graphs or e-commerce tables before and after using augmented reality, is there an increase in effectiveness in e-commerce.

\subsection{User needs}

Analysis of user needs aims to make the system according to user needs, namely the buyers (followers) of the Dapurzone account. Users can view sales product details in the form of 3D modeling on Instagram using an Android smartphone. The application with augmented reality technology can be used by installing the application on an android smartphone and running the application then directing the camera to each flat area [7].

\subsection{Designing Concept}

Field studies relating to the author do by looking at current methods and technologies that are developing at this time, whether the technology currently developing can be implemented in $e$ commerce. The description of the concept that the author of Gagas is an e-commerce application that can display 3D modeling from plates, bowls, glasses and teapots on Instagram and can be used on Android smartphones. Users can use the application using an Android smartphone and Instagram is used as a medium to view sales product details in the form of 3D modeling on each predetermined image [8].

In addition, it is necessary to think about how application illustrations are used with augmented reality technology that will take place. Applications will be made using Unity 3D with the help of VuforiaLibrary and 3ds Max application to create 3D Modeling [9]. In its manufacture there is a marker (User Defined Target) which is downloaded on unity (default unity) and used as a marker, with a marker (User Devined Target) [10]. Then each flat area will be identified so that it will display 3D Modeling plates, cups, bowls, and teapots. The following illustrates the application concept in Figure 4.1 below:

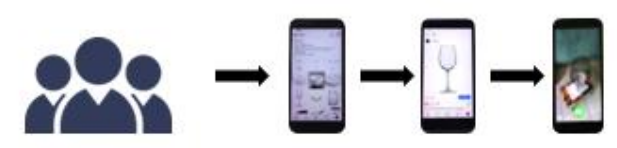

Figure 1. Illustration of Application Concept Design
Image targetplaced on the unity application itself, namely User Defined Target, User Defined Target is for each plane, so that when you want to see 3D objects from the kitchen tool can be seen in each plane. In the VuforiaLibrary each 3D object is inputted into a unit then given a User Definer Target which is used as a marker for a flat plane, after the process is complete then the results are saved and downloaded into the format*.apk[11].

\subsection{Designing Contents}

The content design process will be presented in the form of 3D kitchen tools. In the kitchenzone account istzone there are several kitchen tools that are traded but which will be used as an example of 3D objects are 4 kitchen tools namely plates, cups, bowls, and teapots.

In each image that will be used as a 3D object on the Dapurzone Instagram account such as plates, cups, bowls, and teapots there are information such as: item code, item price, item size, item weight, item material, and order format for the buyer, such as: customer name , the item code, the buyer's address, the buyer's postal code, the mobile number that can be contacted, and at the bottom there will be an Augmented Reality link so that the buyer or follower can see Augmented Reality from the image of the kitchen tool, the buyer or follower can see Augmented Reality on each flat area. The following design contents as follows:

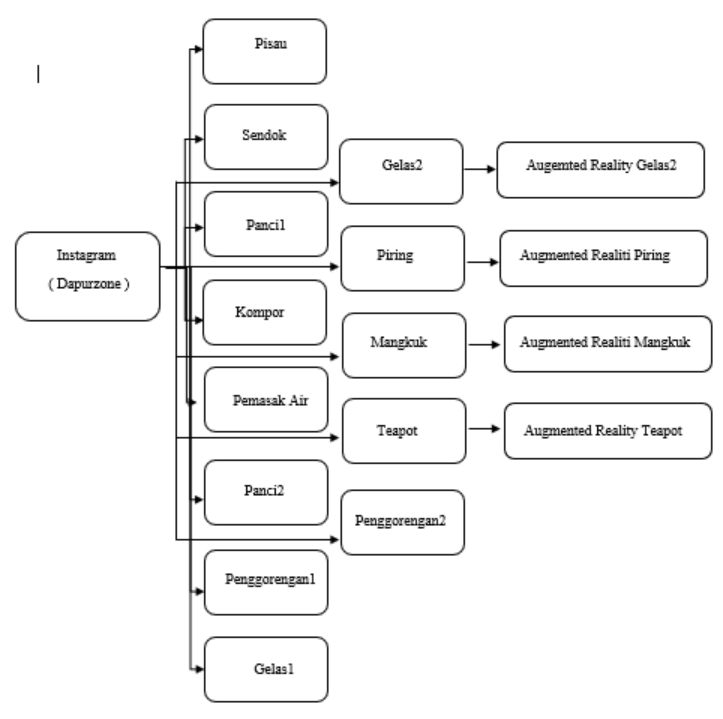

Figure 2. Design of Augmented Reality Ecommerce Content 


\subsection{Designing Applications}

The application design process is the application design process carried out on Unity 3D software which includes importing the * unitypackage database downloaded from the VuforiaLibrary, designing 3D object positions and exporting the application into a format.*.apk[12].

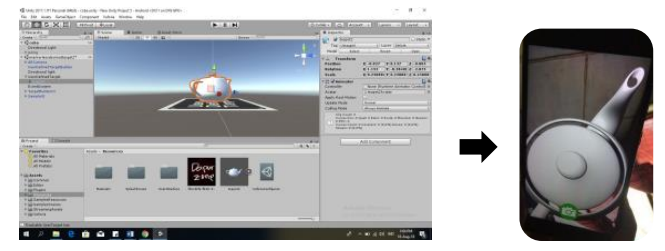

Figure 3.Teapot Page Object

The Augmented Reality application menu page will display $3 \mathrm{D}$ objects from the template that can appear on flat areas.

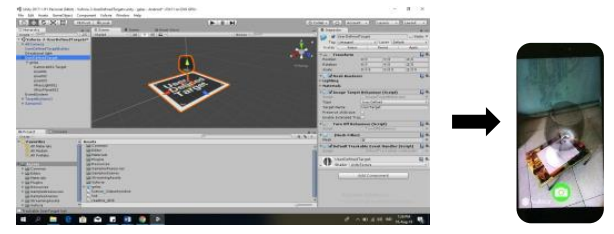

Figure 4.Glass Object page

On the Augmented Reality glass application menu page, will display 3D objects from the glass that can appear on flat areas.

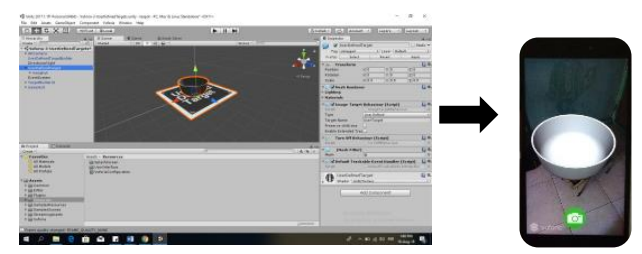

Figure 5.Bowl Page Object

On the bowl menu Augmented Reality application page, will display 3D objects from the bowl that can appear on flat areas.

\section{RESULTS AND DISCUSSION}

\subsection{System Production}

At the start all ideas that were previously designed were created with the help of predetermined software. The production system implements the results of the planning in the process of photographing kitchen utensils that will be uploaded on Instagram, the design of 3D models provides the creation of 3D objects and provides texture materials, as well as the processes that connect to Unity $3 \mathrm{D}$.

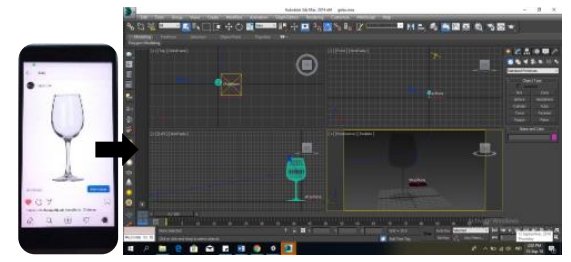

Gambar 6. Example Process of Making 3d Objects

\subsection{System testing}

The system testing process is divided into three stages namely unit testing, system testing and acceptance testing. Unit testing is a testing or testing program consisting of testing each or separately in a multimedia system, both systems are tests of the functioning of the whole multimedia system, and a third test is acceptance testing. acceptance testing is a quality assurance that is the final certification by showing that the system fullfil expected quality standards and the system can be used[13].

\subsection{Unity Testing}

At this stage, is the process that the researchers test the function of each device namely the function of the button, smartphone camera, application and suitability of the marker. The technique used by running the application uses an android smartphone, testing the application, and seeing whether each 3D object appears or not. This is done on the marker in the unity application for each plane. Following is the unit test application, and markers for each plane to display 3D objects are as follows:

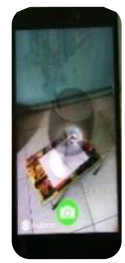

Figure 7. Testing with glass objects 


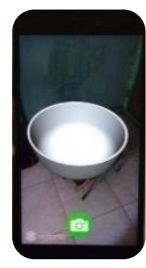

Figure 8. Testing with a bowl objects

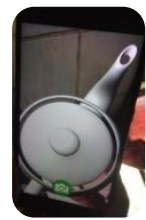

Figure 9. Testing with teapot objects

\subsection{Questionnaire}

Questionnaire is a data collection technique where the respondent fills in the question then after it is filled, they give to the researcher [14]. At the data collection stage, the questionnaire will be designed and distributed to 286 respondents, the questionnaire grid in table 4.3 below.

From the results of the questionnaire obtained data that the gender of the questionnaire filling was $88.8 \%$ female and $11.2 \%$ male as follows:

Jenis Kelamin

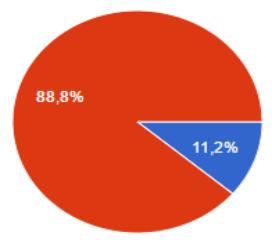
- Laki-Laki

Figure 10. Gender Data Filler Questionnaire

\subsection{Acceptance Testing}

At this stage, researchers want to find out whether there is an increase in effectiveness before and after using augmented reality. So in this study researchers used the Wilcoxon signed rank test for before and after using augmented reality. In this study, effectiveness is measured by looking at if:

a. Value of Enjoyable>Annoying

b. Value of Good $>$ Bad

c. Value of Pleasing > Unlikable

d. Value of Pleasant $>$ Unpleasant

e. Value of Attractive >Unattractive f. Value of Friendly $>$ Unfriendly

g. Value of Understandable >Not understandable

h. Value of Easy to learn >Difficul to learn

i. Value of Easy >Complicated

j. Value of Clear $>$ Confusing

k. Value of Fast $>$ Slow

1. Value of Efficient $>$ Inefficient

m. Value of Practical >Impractical

n. Value of Organized >Cluttered

o. Value of Predictable > Unpredictable

p. Value of Supportive >Obstructive

q. Value of Secure $>$ Not secure

r. Value of Meets Expectation >Does not meet expectation

s. Value of Creative >Dull

t. Value of Inventive $>$ Conventional

u. Value of Leading edge > Usual

v. Value of Innovative >Conservative

Another measurement of the effectiveness standard in this study is to consider the number of followers of the dapurzone account which will have an impact on the number of buyers (increased accuracy before and after using augmented reality). In addition to that, the existing Augmented Reality is pursued in a similar, sized, and colored form with existing kitchen tools, so that many followers of the dapurzone account like and trust, when researchers distribute questionnaires to the dapurzone account followers, they can fill out questionnaires denes pene effectiveness after using augmented reality.

\subsection{Reliability Test}

Reliability test is a measure of a respondent's stability and consistency in answering matters relating to the construction of questions, which are dimensions of a variable and arranged in a form of questionnaire[15].

Reliability tests can be tested in conjunction with all questions. if the alpha value> 0.60 makarealibel, with the following formula:

If the value of alpha $>0,60$ make a realibel, with the formula:

$$
r\left[\frac{k}{(k-1)}\right]\left[1-\frac{\sum \sigma_{b}^{2}}{\sigma_{t}^{2}}\right]
$$

Meaa :

$r=$ instrument reliability coefficient (Cronbach Alpha)) 
$k \quad=$ Number of questions

$\sum \sigma_{b}^{2} \quad=$ number of item variants

$\sigma_{b}^{2} \quad=$ number of variants

The steps of the reliability test, first by finding the total value of the variance on each question item and after that looking for the Cronbach Alpha value(Sujarweni., Endaryanto, 2012).

The steps to find the total variance are as follows:

The numbers entered in the formula can be seen in the appendix

Formula $: r\left[\frac{k}{(k-1)}\right]\left[1-\frac{\sum \sigma_{b}^{2}}{\sigma_{b}^{2}}\right]$

a. Before using augmented reality.

Calculate the total variance for each question:

( P1 ) $\sigma_{b}^{2}=0.837787$

( P2 ) $\sigma_{b}^{2}=1.173807$

( P3 ) $\sigma_{b}^{2}=1.099313$

( P4 ) $\sigma_{b}^{2}=1.132867$

( P5 ) $\sigma_{b}^{2}=1.627383$

( P6 ) $\sigma_{b}^{2}=1.243982$

( P7 ) $\sigma_{b}^{2}=2.484014$

( $\mathrm{P} 8$ ) $\sigma_{b}^{2}=2.81325$

( P9 ) $\sigma_{b}^{2}=3.01352$

( P10 ) $\sigma_{b}^{2}=3.436155$

( P11 ) $\sigma_{b}^{2}=1.753944$

( $\mathrm{P} 12) \sigma_{b}^{2}=1.367636$

( $\mathrm{P} 13) \sigma_{b}^{2}=1.46663$

( P14 ) $\sigma_{b}^{2}=1.321813$

( P15 ) $\sigma_{b}^{2}=1.362986$

( P16 ) $\sigma_{b}^{2}=0.982419$

( P17 ) $\sigma_{b}^{2}=1.067955$

( $\mathrm{P} 18) \sigma_{b}^{2}=1.105386$

( P19) $\sigma_{b}^{2}=1.248681$

( P20 ) $\sigma_{b}^{2}=0.904588$
( $\mathrm{P} 21) \sigma_{b}^{2}=1.03683$

( $\mathrm{P} 22) \sigma_{b}^{2}=1.0043$

Number of item variants:

$\sum \sigma_{b}^{2}=0.837787+1.173807+1.099313+$ $1.132867+1.627383+1.243982+2.484014+$ $2.81325+3.01352+3.436155+1.753944+$ $1.367636+1.46663+1.321813+1.362986+$ $0.982419+1.067955+1.105386+1.248681+$ $0.904588+1.03683+1.00434=33.48529$.

Calculate the total variant:

$\sigma_{b}^{2}=\frac{1660452-\frac{21704^{2}}{286}}{286}=46.77069783$

Calculate coefficient of Cronbach's alpha:

$r=\left[\frac{k}{(k-1)}\right]\left[1-\frac{\sum \sigma_{b}^{2}}{\sigma_{b}^{2}}\right]$

$r=\left[\frac{22}{(22-1)}\right]\left[1-\frac{33.48529}{46.77069783}\right]=0.29758$.

b. After using augmented reality.

Calculate the total variance for each question:

( P1 ) $\sigma_{b}^{2}=0.087069$

( P2 ) $\sigma_{b}^{2}=0.092811$

( P3 ) $\sigma_{b}^{2}=0.21049$

( P4 ) $\sigma_{b}^{2}=0.184419$

( P5 ) $\sigma_{b}^{2}=0.063121$

( P6 ) $\sigma_{b}^{2}=0.75657$

( P7 ) $\sigma_{b}^{2}=0.989682$

( P8 ) $\sigma_{b}^{2}=0.370126$

( P9 ) $\sigma_{b}^{2}=0.35338$

( P10 ) $\sigma_{b}^{2}=0.399853$

( P11 ) $\sigma_{b}^{2}=2.550705$

( P12 ) $\sigma_{b}^{2}=1.902993$

( $\mathrm{P} 13$ ) $\sigma_{b}^{2}=1.819126$

( P14 ) $\sigma_{b}^{2}=1.950595$

( P15 ) $\sigma_{b}^{2}=0.984039$

( P16 ) $\sigma_{b}^{2}=0.491584$

( P17 ) $\sigma_{b}^{2}=0.334401$ 
( P18 ) $\sigma_{b}^{2}=0.25657$

( P19) $\sigma_{b}^{2}=0.075966$

( P20 ) $\sigma_{b}^{2}=0.187707$

( P21 ) $\sigma_{b}^{2}=0.338425$

( $\mathrm{P} 22) \sigma_{b}^{2}=0.139566$

Number of item variants:

$\sum \sigma_{b}^{2}=0.087069+0.092811+0.21049+$ $0.184419+0.063121+0.75657+0.989682+$ $0.370126+0.35338+0.399853+2.550705+$ $1.902993+1.819126+1.950595+0.984039+$ $0.491584+0.334401+0.25657+0.075966+$ $0.187707+0.338425+0.139566=14.5392$.

Calculation of total variation:

$$
\text { 1. } \sigma_{b}^{2}=\frac{3014292-\frac{29328^{2}}{286}}{286}=23.91227
$$

To measure coefficient of Cronbach's alpha:

$$
r=\left[\frac{k}{(k-1)}\right]\left[1-\frac{\sum \sigma_{b}^{2}}{\sigma_{b}^{2}}\right]
$$

2. $r=\left[\frac{22}{(22-1)}\right]\left[1-\frac{14.5392}{23.91227}\right]=0.410643$

The conclusion of the reliability assessment is: Reliability test results before and after using augmented reality get the results of the Cronbach Alpha coefficient: 0.29758 (before using augmented reality) and 0.410643 (after using augmented reality) with the condition that if the alpha value $>0.60$ macarealibel. With the values of $0.29758<0.60$ and $0.410643<0.60$, it can be concluded that the results of the Cronbach Alpha coefficient on the reliability test before and after using augmented reality are not reliable. The non-reliable results obtained may be due to the lack of dissemination of the questionnaire to the dapurzone account followers or due to the ignorance of the followers on how to fill the questionnaire, in accordance with the advice and direction of the author.

\subsection{Normality test}

a. Normality test is performed on data before using augmented reality

Median 40.79220779

Standard deviation $\quad 46.6238845$

We obtain:
$\mathrm{L}_{0}=$ The largest liliefors value (The green colour in the column $|\mathrm{Fz}-\mathrm{Sz}|$.

$\mathrm{L}_{0}=0.184314985$

$$
\text { 3. } \text { Ltabel }=\frac{0,886}{\sqrt{n}}=\frac{0,886}{\sqrt{40}}=0,1400
$$

The formula if $\mathrm{L}_{0}<$ Ltable the data is normally distributed, where $\mathrm{L}_{0}=0,184314985>$ Ltable $=$ 0,1400 , we assume the data is not normally distributed.

b. Normality test is performed on data after using augmented reality

\section{Median 40.87012987 \\ Standard deviation $\quad 73.942099$}

We obtain:

$\mathrm{L}_{0}=$ The largest liliefors value (The green colour in the column $|\mathrm{Fz}-\mathrm{Sz}|$.

$\mathrm{L}_{0}=0.320006709$

$$
\text { Ltable }=\frac{0,886}{\sqrt{n}}=\frac{0,886}{\sqrt{40}}=0,1400
$$

The formula if $\mathrm{L}_{0}<$ Ltable the data is normally distributed, where $\mathrm{L}_{0}=0.320006709>$ Ltable $=$ 0,1400 we assume the data is not normally distributed.

The conclusion of the normality test using augmented reality before and after has results not reliable, therefore it was re-tested using a Wilcoxon test with paired-samples t-test. Wilcoxon test with paired-samples t-test is used as the final result which means it used to described for those test with data that is not normally distributed.

3.12. Wilcoxon test with pairedsamples t-test

a. The Statistical Poses hypothesis

Ho: $\mu 1=\mu 2$ (There's no increase in effectiveness after using augmented reality)

$\mathrm{H}_{1}: \mu 1 \neq \mu 2$ (Increased efficiency after using augmented reality)

The formula :

$$
\text { 4. } \mathrm{Z}=\frac{T-\sigma_{T}}{\sigma_{T}}=\frac{T \frac{N(N+1)}{4}}{\sqrt{\frac{N(N+1)(2 N+1)}{24}}}
$$


Mean:

$\mathrm{T}=$ Number of positive ratings or number of negative ratings.

$\mathrm{N}=$ The number of pairs is not the same value.

$\alpha=0,05$

b. The table marked Wilcoxon for the pretest.

Based on the table obtained:

Indication "+"a total of 95 with a total ranking of 10.205 .

Indication "_."a total of 59 with a total ranking of 1,621

Ignored data $($ valuable 0$)=0$.

$\mathrm{N}=154-0=154$ (different amount of data)

$\mathrm{T}=1.621$

c. Determine the value of $\mathrm{Z}$ table

$$
\begin{aligned}
& \mathrm{Z}=\frac{T-\sigma_{T}}{\sigma_{T}}=\frac{T \frac{N(N+1)}{4}}{\sqrt{\frac{N(N+1)(2 N+1)}{24}}} \\
& \mathrm{Z}=\frac{T-\sigma_{T}}{\sigma_{T}}=\frac{1.621-\frac{154(154+1)}{4}}{\sqrt{\frac{154(154+1)(2 * 154+1)}{24}}}=-3792,1
\end{aligned}
$$

d. Determine the value of $Z$ table

Use $\mathrm{Z}$ tables with two parties test $\alpha / 2=$ $0,05 / 2=0,025$. Curve area $F(z)=0,5-$ $0,025=0,4750$. Thus, the $\mathrm{Z}$ coordinate table is obtained $=1,96$.

e. Testing criteria

Determine the location of the $\mathrm{Z}$ table, whether it is in the area of rejection of the hypothesis $\mathrm{Ho}$ or in the area of acceptance of the hypothesis $\mathrm{Ho}$. Based on the $\mathrm{Z}$ table values obtained, the $Z$ table values are in the rejection area of the hypothesis $\mathrm{Ho}$.

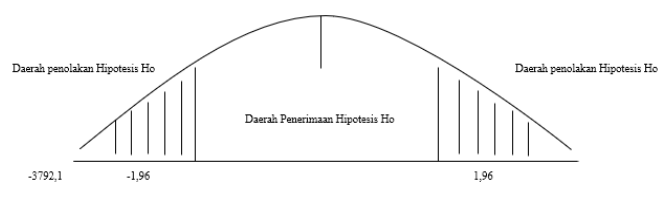

Figure 11. Testing criteria

\section{f. Conclusion}

Because the value of $\mathrm{Z}=-3792.1$ is in the rejection area $\mathrm{H} \circ$ then accept $\mathrm{H}_{1}$. Thus it can be concluded that there is a difference that is an increase in effectiveness after using augmented reality.

\section{CONCLUSIONS AND SUGGESTION 4.1. CONCLUSION}

The results of the analysis of this study are the data before and after using non-reliable augmented reality with a value of $0.29758<0.60$ and $0.410643<0.60$ and abnormal data with a value of $\mathrm{L}_{0}=0.184314985>$ Ltable $=0.1400$ and $\mathrm{L}_{0}=0.320006709>$ Ltable $=0.1400$ but after further testing using Wilcoxon different test paired samples showed the results that $\alpha=$ $0.05, \mathrm{~N}=154, \mathrm{~T}=1.621$ and $\mathrm{Z}=-3792.1$ while the $\mathrm{Z}$ coordinate table $=1.96$. Because the start $\mathrm{Z}=-3792.1$ is in the rejection area $\mathrm{H} \circ$ then accept $\mathrm{H}_{1}$, which means there are differences before and after using augmented reality means that there is an increase in the effectiveness of ecommerce after using augmented reality, based on the results of questionnaire data on 286 respondents. Thus it can be concluded that there is a difference that is an increase in effectiveness after using augmented reality. With the increase in effectiveness in e-commerce using augmented reality, augmented reality technology can be used as a medium for e-commerce sales on Instagram.

\subsection{SUGGESTION}

Based on the results of existing research, the researchers suggest that further research be carried out on improving e-commerce using augmented reality on other e-commerce sites such as Facebook, because on social media Facebook already has an augmented reality menu. So if done on Facebook social media it will be even easier to do research by subsequent researchers

\section{REFERENSI}

[1] S. M. Dr. S.Sahabuddin, "TRANSAKSI KONVENSIONAL DENGAN TRANSAKSI E-COMMERCE (Pendekatan Komparatif)."

[2] A. . Kalakota, $\mathrm{R}$ and Whinston, "Electronic Commerce: A Manager's Guide, New Jersey,” Addison-We., 1997.

[3] B. (ed) A. Garner, "Black's Law Dictionary seventh Edition," New York., 1999.

[4] Plunkett, "Elektronik Ecommerce: A 
Managerial and Social Networks perspective, Ninth Edition, Efraim Turban dkk," Switzerland., 2017.

[5] Dr Desti Kannaiah dan Dr R. Shanthi, "The Impact of Augmented reality on Ecommerce," Singapore, 2015.

[6] M. Billinghurst, A. Clark, and G. Lee, "A survey of augmented reality," Found. Trends Human-Computer Interact., vol. 8, no. 2-3, pp. 73-272, 2014, doi: $10.1561 / 1100000049$.

[7] dan P. H. Deepak Dwarakanath, Carsten Griwodz, "Robustness of 3d Point Positions To Camera Baselines In Markerless AR Systems," Oslo Norway., 2016.

[8] A. S. Miftakhul Jamal, "Penerapan Teknologi Augmented reality Sebagaimedia Promosi Berbasis Android Pada Toko Jati Tresno," J. Tek. Inform. Fak. Ilmu Komputer, Univ. Dian Nuswantoro., 2015.

[9] S. L. Tseng-Lung Huang, "A model of acceptance of augmented reality interactive technology: the moderating role of cognitive innovativeness," Taiwan: College of Management, Yuan Ze University, 2014.

[10] dan M.-H. T. Li-Chen Wu, I-Chen Lin, "Augmented reality Instruction For Object Assembly Based On Markerless Tracking," National Chiao Tung University, 2016.

[11] M. K. R. Neetika Gupta, "An Experimental Study Of Markerless Image Registrations Methods On Varying Quality Of Image For Augmented reality Applications," India, 2017.

[12] C. Rizki, Hariadi, "Markerless Augmented reality Pada Perangkat Android," Surabaya, 2012.

[13] S. Bagong, "Metode Penelitian Sosial," Jakarta: Kencana Prenada Media Groupp, 2005.

[14] Sugiyono, "Metode Penelitian Kuantitatif, Kualitatif dan R\&D,"
Bandung, 2011.

\section{[15] $\begin{aligned} & \text { P. Sujarweni, V. W., \& } \\ & \text { "Statistika Endrayanto, } \\ & \text { Untuk }\end{aligned}$ \\ [15] $\begin{aligned} & \text { P. Sujarweni, V. W., \& } \\ & \text { "Statistika Endrayanto, } \\ & \text { Untuk }\end{aligned}$ Yogyakarta: Graha Ilmu, 2012. Yogyakarta: Graha Ilmu, 2012.}

